\title{
Privacy Awareness of Students and Its Impact on Online Learning Participation - A Case Study
}

\author{
Birgy Lorenz, Sonia Sousa, and Vladimir Tomberg \\ Tallinn University, Institute of Informatics, Narva road 25, \\ 10120, Tallinn, Estonia \\ \{Birgy. Lorenz, sonia.sousa, vladimir.tomberg\}@tlu.ee
}

\begin{abstract}
This paper is based on a survey that addresses two main hypotheses that there is a positive correlation between students' level of participation and their privacy awareness, and students with high levels of privacy awareness need to be assured that their open learning activities are protected from potential threats in order to achieve positive results. Results show that in fact there is a correlation between students' awareness of privacy and their predisposition to share and to participate in open leaning contexts. This is especially evident when students share their school assignments, grading results and teacher's feedback or even their comments with others.
\end{abstract}

Keywords: privacy, trust, e-learning, personal learning environments, LePress.

\section{Introduction}

Our study explores the area of privacy awareness and trust in open or semi-open learning environments. We claim that by understanding the interrelation between students' privacy awareness, their attitudes and beliefs towards sharing in an online learning environment, we will are able to contribute to the design decisions regarding the blog-based tools. The featured example of such a blog-based PLE tool is LePress ${ }^{1}$, which is an enhancement of the most popular blog engine WordPress.

\section{Background}

Privacy and security researchers in the e-learning domain often focus on a technical area like logging and tracking [1], environments security (accountability, safeguards, individual access, administrative policies, disclosure, retention) [2] or sensitive data misuse, and theft [3]. Nevertheless the questions related to personal privacy have come up [4], as some researchers now included the topics of data ownership and privacy [5].

The status of e-learning in Estonia has its own clear peculiarities. At the high school level, the new National Curricula states an obligation for every school to use

${ }^{1}$ http: //wordpress.org/extend/plugins / lepress-20/

T. Ley et al. (Eds.): OST 2012, IFIP AICT 395, pp. 189-192, 2013.

(C) IFIP International Federation for Information Processing 2013 
an e-learning environment [6]. At university / vocational school level, there are many open and non-open solutions to choose from, e.g. Wikiversity, Moodle, Blackboard, IVA, LeMill, WordPress, etc [7].

Burdened with new professional responsibilities, primary and secondary school teachers have raised serious questions about personal and data protection in these environments and also suggested that learning experience shouldn't be public to allow children an opportunity to make mistakes [8]. As a result, some schools have chosen closed learning environments like Moodle. At the same time closeness can be a mirage - especially when security holes are not patched and data is leaking anyway.

Thus the main aim of this study is to provide a further understanding how does the students' awareness of potential privacy threats influence students' learning experience and suggest some solution. For that we rely also on the theory about privacy by Razavi and Iverson [9], [10].

\section{$3 \quad$ Methods}

We carried out an empirical study among students from Pelgulinna Gymnasium and Tallinn University, with two main hypotheses: 1 . There is a positive correlation between the subject's level of participation and their level of privacy awareness; 2 . students with high levels of privacy awareness need to be assured that their open learning activities are protected from potential threats in order to achieve positive results.

The questionnaire was conducted by using an open source web application called LimeSurvey and used Likert scale as well as open-ended answers. Sixty-one (61) anonymous responses were collected during November 2011. The survey included 25 questions, divided into three main groups: (1) background, (2) privacy awareness, and (3) predisposition to participate in open learning activities ${ }^{2}$.

\section{$4 \quad$ Results}

According to data, most participants are from Tallinn. The majority attended high school graduation level and most of them had no earlier experience with blog-based tools in learning contexts.

Regarding the first hypothesis, a positive and significant correlation was found between the subjects' predisposition to participate and their privacy awareness. More specifically, a bivariate analysis (Spearman's) showed a statistically significant correlations on the following issues: (1) those who publish often also agree that it is very easy to anonymously find information and pictures of others on the web $(\mathrm{r}=.272 *, \mathrm{r}=.267 *$ and $\mathrm{r}=.264 *$ ); (2) those who publish often (school assignments on the web) tend also to agree that it is very easy to post comments anonymously on the web $(r=.3$ (Sig. (2-tailed)=.019) (3) those who publish often (something about a

${ }^{2}$ Please see the following address http://goo.gl/xCTy8 for further information re-garding survey questions. 
teacher or a school colleague) also agree that it is very easy to post comments about somebody (friends, teacher, school) on the web under a false name ( $\left.\mathrm{r}=.311^{*}\right)$ and also agree that it is not easy to permanently remove content that others have posted about them on the web $(\mathrm{r}=-.319 *) ;(4)$ again, those who publish often also agree that it is not safe to take part in open forum discussions $(\mathrm{r}=-.279 *)$; but argue that it is safe to read teachers' feedback in closed learning contexts $\left(\mathrm{r}=.286^{*}\right)$.

Concerning the second hypothesis, again a positive correlation was found between student's privacy awareness and the need to be assured that they are interacting in a safe place. These concerns are especially expressed by the students who believe that teachers should always make extra efforts to provide support to assure that their learning activities are protected from privacy threats. This issue is mostly correlated with their beliefs that (1) it is very easy to post comments in the web anonymously $(\mathrm{r}=.332 * *), \quad(2)$ it is very easy to anonymously see their friends' information and pictures on the Facebook $(r=.279 *)(3)$, or even with their belief that an email account is a safe place to exchange messages $\left(\mathrm{r}=.255^{*}\right)$; and (4) that a closed learning environment is a safe place to read teacher feedback ( $\left.\mathrm{r}=.416^{* *}\right)$; but (5) it is not safe to share (e.g. work-related resources or to exchange comments) in social e-tools like Facebook or Google+ $\left(\mathrm{r}=-.270^{*}\right)$. Also, most students who agree that it is safe to read and send e-mail through an email base account claim that (1) the teacher's grading information $(\mathrm{r}=.373 * *)$, (2) homework comments $(\mathrm{r}=.284 *)$ and (3) feedback $\left(\mathrm{r}=.255^{*}\right)$ should remain private by default. Again a negative correlation was found, though between those students who believe that it is safe to share using social e-tools (work-related resources or exchange comments) and their belief that (1) teacher's feedback $\left(\mathrm{r}=-.253^{*}\right),(2)$ homework submissions $\left(-.267^{*}\right)$ and (3) grading information $(\mathrm{r}=-.282 *)$ should remain private by default ${ }^{3}$.

\section{Discussion}

We conclude that the students who socialize the most on the Internet tend to be more aware of potential privacy threats of this communication medium and need assurance that they are interacting in a protected and secure environment. We also concluded that students in a virtual environment tend usually not to distinguish between private and educational social interactions and this might be a potential threat for their communication environment. Students don't usually filter their posts or comments when in social networks; though some of them feel that their rights and privacy may be violated if their posts or comments are open to everybody. This indicates that these matters should be addressed more at schools. Some environments convince that they store data safely, yet they may sell it to others or just have weak privacy settings.

For the future we are going to repeat the study, but also look behind of the obvious privacy needs what have come up. Unanswered questions are related to the digital divide between students and teacher changing role to provide safe learning environment.

\footnotetext{
${ }^{3}$ Please see the following address http: / / goo.gl / $\mathrm{xCTy} 8$ for further information.
} 


\section{Conclusion}

The main outcome of this study is that from a learners' point of view, students need to be ensured that their online learning activities are protected from potential privacy threats. Based on that knowledge we aim to implement comfortable conditions that will stimulate students for self-regulated learning. It means that from a blog-based PLE perspective (e.g. when a student uses LePress or another PLE tool) the student should be able to define access restrictions to his/her resources or information. A paramount idea is that grading, homework feedback or comments should in many cases stay private. Our study indicates that privacy is becoming more significant as schools are starting to use open and semi-open PLEs as obligatory tools to educate students. The findings of this study allow us to start a new redesign iteration of LePress software for PLE privacy needs.

\section{References}

1. May, M., Sébastien, G.: Privacy Concerns in E-learning: Is Using Tracking System a Thread? International Journal of Information and Education Technology 1(1), 1-8 (2011)

2. El-Khatib, K., Korba, L., Xu, Y., Yee, G.: Privacy and security in e-learning. International Journal of Distance Education Technologies 1(4), 1-19 (2003)

3. Hayaati, N., Alwi, M., Fan, I.-S.: Information Security Threats Analysis for E-Learning. Elearning, 285-291 (2010)

4. Next Generation Learning, Analysis of emerging trends affecting the use of technology in education. Learning (September 2008)

5. Gurses, S., Rizk, R., Gunther, O.: Privacy design in online social networks: Learning from privacy breaches and community feedback. Information Systems Journal (2008)

6. Vabariigi Valitsus, Gümnaasiumi riiklik õppekava (2011), https: / / www.riigiteataja.ee/akt/114012011002

7. Estonian Information Technology Foundation (EITF). E-Learning Development Centre Strategy, Tallinn (2012)

8. Piir, M.: Suletud ja avatud õpikeskkond, e-õppe ajakiri (2011), http: / /www. etu.ut.ee/kevad-2011/opikeskkonnad/

9. Hansen, M.: Marrying Transparency Tools with User-Controlled Identity Management. The Future of Identity in the Information Society 262, 199-220 (2008)

10. Razavi, M.N., Iverson, L.: A grounded theory of information sharing behavior in a personal learning space. In: Proceedings of the 2006 20th Anniversary Conference on Computer Supported Cooperative Work, pp. 459-468 (2006) 